Homalle, the chill is often wanting; there may be no rise in temperature, pain is absent or of short duration, characteristic expectoration and râles are seldom present and the cough is infreculuent.

lobar pneumonia, occurring during the first two weeks of typhoid fever, is the subject of much discussion. It sometimes occurs as a simple complication, and at other times there seems to exist a kind of transition form between the two diseases.

I ćpine" in his article on "pneumonia," expresses his belief in a form of pneumonia due to the local infection of typhoid fever, in which the pulmonary symptoms are the noticeable ones, and the abdominal symptoms are slight. 'Ihis he calls pneumo-typhoid. Hoffmann ${ }^{8}$ classes two of the 18 cases of lobar pneumonia which he found as pneumo typhoid. A short history of one of these cases will illustrate the disease.

Mr. K., 2 I years of age, began to suffer with headache, September 4, and had nosebleed. September I 3 went to the hospital. The breathing was labored, there were râles in both lungs and dulness and bronchial breathing in the lower right lung. On the 18th the patient died. On autopsy, croupous pneumonia of the right side and infiltration of Peyer's patches and ulceration of the ilium were found. Had the latter lesions been alssent, Hoffmann would have considered the case one of pneumonia with typhoid synutoms. ['Typhoid pneumonia. Flint.]

Longet thinks that there are cases of pneumotyphoid in which there are no intestinal symptoms, and in which on autopsy no intestinal lesion can be found. He believes that typhoid poison in severe cases makes its entrance through the lungs or has its seat there. E. Wagner, ${ }^{b}$ in concluding an article on the subject of pneumo-typhoid, says that, with our present knowledge, it is impossible for us to decide the exact neurological position of the disease. Hixact knowleclge of the specific germ of the clisease will clear this doubt.

Cardiac weakness, so common in typhoid fever, is a direct cause of several of the pulmonary complications. These complications are in no way peculiar to typhoid fever, but may occur in any asthenic fever. 'They are more common in typhoid fever on account of the duration and intensity of the fever. Passive congestion of the lungs often occurs as the result of cardiac weakness. 'Ihis passive congestion may lead to cerdema. The passive congestion is most likely to occur in dependent portions of the lungs. It may be unilateral if the patient for any cause has aśsumed a position upon one side, but when it occurs it is usually bilateral. 'This form of congestion has been called hypostatic. When the parts, through oedema, become devoid of air, an appearance resembling the spleen may be seen. 'This is splenization. Another result of fectble action of the heart is the formation of thrombi. 'These becoming detached, may cause embolic infarction of the lungs. Emboli may arise from some septic source. Boldtdammer reports five

$1 \mathrm{~J}$.oc, cit.

'Nouveats Jict, de Med, et de Chirurg, xxviii.

s oc. cit.

II,Union M Md., xxxviii, 760 .

IDeutsch. Archiv. f, klin,, Med, 1884, xxxv, 19t.

Ioc. cit. deaths from embolic pneumonia among 783 cases of typhoid fever. The origin of the emboli was in one case the right side of the heart, in another an old perityphlitic abscess, in a third case an abscess of the thigh. The origin in the other cases was not discovered. 'These emboli may cause gangrene of the lungs, and the pulmonary tissues breaking down, pneumothorax may result. Embolism of the pulmonary artery and instant death is not a rare occurrence.

like pneumonia, pleurisy in typhoid fever may give little indication of its presence. It occurs frequently, but unless extensive, it is very apt to escape notice. Empyema also occurs, and sometimes independently of pneumothorax. Acute miliary tuberculosis sometimes occurs as a secumel to typhoid fever, but probably not from any direct cause. Phthisis also develops sometimes as a result of the nonabsorption of secretions which have not been thrown off during the period of great prostration.

Hamoptysis, according to Homalle,' occurs during typhoid as the result of a hamorrhagic infarction. It may also occur as a symptom of concurrent phthisis.

The extreme exhaustion of many typhoid cases makes the frequent examination of the patient more. difficult. For this reason and from the lack of symptoms many of the above complications undoubtedly exist at times and escape unnoticed. Given a severe case of fever with high temperature and marked abdominal symptoms, diarrhera, abclominal distension and tenderness with more or less stupor, is the frequent examination of the patient's chest, rechuiring moving of the patient, necessary or desirable? Flint advises the frequent change of the position of the patient with a view to prevent hypostasis. 'This certainly is desirable. Patients who have kept a fixed position for a long time will often give signs of hypostasis, which will disappear on assuming another position. If this plan be carried out, there will be no additional fatigue to the patient from the application of the stethoscope. By its use we may learn more of the real strength of the heart than the pulse or the heart sounds could give us, and we may get an earlier warning of the necessity for increased efforts to sustain the heart's action.

Antipyretic measures undoubtedly decrease the frequency and severity of pulmonary complications. I iebermeister" reports concerning i 743 typhoid patients, alsout one-half of whom were treated by cold baths, that the number of cases of pulmonary consolidation was reduced from 14.4 per cent. to 10.9 per cent., and that the mortality of these cases was reduced from 54 per cent. to 34 per cent.

\section{PENETRATING WOUNDS OF THE ABDOMINAL CAVITY."}

\section{BY s. M. HAMILTON, M.1),} of MONMOUTH, II.T.

Penetrating wounds of the abdominal cavity, with injury to any one of the contained viscera, may be

IJ.oc. cit.

"Read hefore the Mibiary Tract Medical Society, Nov. 10, 2885. 
considered if not necessarily fatal, yet always doubtful of favorable termination under any course of treatment. 'The probabilities of not one, but several of the abdominal organs being implicated in the injury, the danger from surgical shock, concealed hamorrhage, and local or general peritonitis, are considerations of extreme gravity. This paper is intended to be more suggestive than discursive, and will be confined to a single division of the subject, namely: the management of wounds of the intestine, lacerated or incised, from missile, or pointed instrument, penetrating or traversing the abdominal cavity.

Until a very recent period the history of these cases is a chapter of dismal failures. A minute analysis of the literature of the subject would be fuil of instruction and interest, but it is too extensive for a paper like this, and the records are open and familiar to all. It is only within a very few years that anything better than the expectint and palliative treatment in these cases has been attempted. It is true that Larrey and some of his cotemporaries marle some attempts at surgical interference, but so far as the records show, the enlargement of the external wound was confined to barely as much as was necessary to find, and close with suture, a wound in the intestine; whilst no mention is made of that more important procedure (without which all else will be vain), the thorough cleansing of the peritoneal sac of all blood-clots and irritating material which, in almost all cases, escape from the wounded gut.

The surgical history of the late war records about eighty per cent. of deaths from this injury. In but very few cases was there any departure from the expectant and palliative plan of treatment. The tables include wounds from sabre, bayonet and bullet, and pieces of shell, the two last, of course, by far the most numerous. Of nine cases of bayonet wound, six recovered without any sjecial surgical interference. In at least two there was room for doubt as to the fact of intestinal perforation at all. In the others, the evidence is conclusive that the gut was wounded, but under such favorable conditions that the rent was sufficiently closed on the withdrawal of the weapon to prevent facal infiltration, and permaaptly, after a spell of local inflammation. It is quite apparent in these nine cases, that the form of the weapon had a great deal to do with the favorable result. The bayonet has no cutting edge, is gener-
ally blunt-pointed, smooth and polished. $A$ wound
from it from it approximates that made by a trocar. 'The to sues are not cut, but separated, have a tendency instrumg back into place on the withdrawal of the (Gument, and close up the wound of entrance.

dangerous wot wounds are far more likely to produce for a buts consequences. Yet it is quite possible from bullet, even of large size, to traverse the belly ing the interear, or from side to side, without woundthe ime intestine, or serionsly injuring any other of is found int viscera. One case of this description etrated in my own experience. $A$ musket ball penand a the abdominal wall one inch to the left of through little above the umbilicus, passed directly

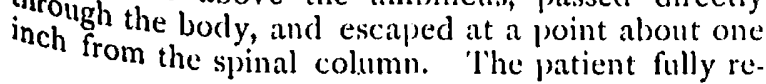

covered, without any bacl symptoms except those which ustually attend a moderate attack of local peritonitis. 'lhere was in this case conspicuous absence of the protracted and unmanageable shock which so often attends cases of wounded intestine, but little pain, and no rapirlly developed meteorism; and to confirm the correctness of the diagnosis, the patient had regular discharges of normal feces about every second day, until his complete recovery took place. I believe it quite in the range of possibility for very small missiles, such as bird-shot, to penetrate the bowel and the punctures close up at once, like the wound of the hypodermic needle or small trocar, and give but little trouble. One such case I have seen. It needed no special treatment, and fully recovered.

These rather tedious details are given to give emphasis to the doctrine that even here, in these cases of severe abdominal injury, the claims of conservative surgery are by no means to be overlooked.

'The evidence of serious intestinal lesion is generally clear and conclusive. 'The shock is marked and profouncl, and disinclined to yield to treatment from the first. The small thread-like pulse, cold, clammy skin, and the shrunken hyppocratic face, show an alarming condition of nervous prostration. Very often, but not always, there is bilious or stercoracious vomiting. Always great pain, and rapidly developed meteorism. If the external wound is large, sulphuretted hydrogen, or fiecal matter, may be detected by sight or smell. Aside from this last (which is conclusive), the rapidly developed meteorism, which is always present, possesses more diagnostic value than anything else. It is of course caused by the escape of gas from the torn intestine into the peritoneal sac. 'These are the symptoms generally present. They are exaggerated or lessened, according to the situation and extent of the internal injury. 'They seem to be plain and conclusive, and easily understood on paper, but I presume that in many of the casses there is a wide margin for mistakes in diagnosis; mistakes which, on the one side, may subject the patient to a needless and dangerous operation, and on the other side, cut him off from his only hope of safety. I know of no situation in which a surgeon may be placed, where rapid and correct deductions, from symptoms to conditions, are so necessary as in these cases of penetrating wounds of the belly. What is the matter? is the all-important question, and there is but little time which can safely be given for its solution.

For obvious reasons, wounds of the small intestine are much more dangerous than those of the large. A missile traversing that part of the cavity almost certainly will cut across not one, but several, folds of the gut, making not one, but many wounds by which poisonous gas and facal matter are poured out upon the sensitive peritoneum. Added to this is its greater mobility from outside disturbance and peristaltic action, lessening thus the chances of cure by adhesive inflammation between the folds of the per. itoneum. Wounds of the large intestine are less dangerous because it is in some degree a fixture in the abdominal cavity, is less dislocated or disturbed 
by peristaltic action, and a part of it is not covered by peritoneum. A wound involving this uncovered portion of the large intestine alone, should have less of the dangerous element in it than the same amount of injury to any other part of the intestinal tube.

The general indications for treatment of these cases are so plain that no one need err. Perfect rest, abstinence from food for several clays, stimulation until reaction takes place, and opium from the first hour should be given freely, to yuict the peristaltic action of the bowel, and keep the irritable nervous system in subjection. 'Ihis last is of vital importance in all cases of abdominal injury, when peritonitis, local or gencral, is to be expected, whilst in cases of intestinal lesion it allays the terrible pain and prevents, to some extent, the pouring out of gas and fiecal matter into the peritomeal cavity, by its power over the muscular fibre of the bowel. 'The constitutional effect of mercury would seem to be indicated in cases of this kind where a high grade of peritoneal inflammation is expected. Its purgative action should be carefully guarded ly a sufficient amount of opium, and the remedy stopped as soon as the mercurial fuetor of the breath is noticed.

The main object of this paper is to call attention to the surgical treatment of certain cases of abdominal injury which, if left to themselves, almost without exception terminate fatally. I refer to cases of gunshot wounds involving onc or more folds of the intestine. The cases are as desperate as can well be imagined, and if let alone, or subjected to general treatment alone, there is nothing in prospect for them but a speedy and grievously painful death. The surgical expedients carried out by larrey and others were attended with little success. They seemed to have a great fear of wounding and exposing the peritoncum, and contented themselves with as little conlargenent of the external wound as was necessary to reach and close the wound in the intestines. It is only recently that surgeons have learned that the peritoneal membrane is but little more susceptible of inflammatory destruction than other parts of the human anatomy. The modern operation of ovariotomy teaches us that the aljdominal cavity may be laid open from ensiform cartilage to pubes, its contents exposed to the atmosphere for hours, and the peritoneum cut and torn very extensively, without the occurrence of fatal traumatic peritonitis. 'The earlier operators for ovarian disease urged as a reason for surgical interference that the disease, if left to itself or subjected to any other treatment known to the profession, was necessarily fatal, sooner or later. It was a good philosophical reason for a bold and hazardous experiment, and probably, outside of such a consideration, no surgeon would have had the hardihood to undertake such an operation. The beneficent result is, that now more than seventy-five per cent. of these necessarily fatal cases of disease are completely and permanently cured. The same reason for operative procedure is good in these cases of woundedintestine. Alsolutely nothing but death can be expected, preceded by many hours or days of unspeakible agony.

In looking over the literature of the cases in which laparotomy has been resorted to, even those lately performed, one fact seems very prominent, that the old fear of peritoneai injury still sticks in the minds of some operators, and stands in the way of that carefulness of detail and thoroughness which alone can secure and deserve success. 'The last case I have seen reported is one by Dr. Parke, of Chicago, the unfavorable result of which was no doubt owing to some blood clots, partly disorganized, found in the peritoneal cavity. 'They had no doubt been overlooked in the dressing. 'The thorough exploration of the cavity was rendered difficult, or impossible, by the faulty primary incision, made through the track of the ball, far over to the left side, instead of in the linea alba. 'The incision should be central without reference to the extermal wound, and large enough to expose the entire cavity to the closest inspection, so that every wound shall be discovered and secured by stitch or suture, all hemorrhage controlled, and alrove all, a thorough cleansing of the peritoneal sac from blood clots and any licpuid or solid foreign material which may have escaped from the intestinal canal.

If any one imagines that this is not a tedious and difficult operation, it is my opinion that his first case will afford him a rude awakening from a foolish dream. I am told that it is not always an easy matter to find these wounds, especially of the small intestine, and still oftener is it difficult to isolate them, so that they may be properly closed. 'Then there are the different kinds and sizes of solution of continuity, from complete division, requiring invagination of the gut, to the small puncture, requiring but a single ligature, all taxing to their utmost the skill, patience and the ingenuity of the operator. Nothing should be neglected, be the time long or short. liverything for the safety of the patient should be done in the most thorough manner possible under the circumstances.

I believe that any and every form of stitch of ligature known to the dressmaker or the surgeon may be needed ir: these cases. 'The glover's stitch, the basting stitch, the interrupted suture, and the simple ligature, all may have their uses according to the kind, shape, and extent of the injury to be repaired. Operators have used iron wire, silver wire, catgut, animal tendon, and I know not what else, for this purpose. But I believe most operators have gone back to good old-fashioned silk. And why not? It is animal fibre, in as minute division as anything known consistent with the necessary strength. I believe that experience proves it as good as the best for closing these and all other kinds of wounds. Post-mortem evidence is conclusive that the heavy silk, stump ligature, used in ovariotomy, and dropued into the peritoneal cavity, disappears so entirely within a year, that not a shred of it can be found.

I hardly know what to say about "l isterism" in connection with laparotomy for wounded intestine. I believe the spray is mostly abandoned. Many consider it an agent of evil, rather than good. We all use a weak solution of carbolic acid to bathe hands and sponges and instruments. Is it merely a habit, a "fashion," as much honored in the breach as the olsscrvance? In my opinion the largest logic 
which can be extracted from the "noisy pother" of Mr. Lister and his enthusiastic admirers is, that extreme cleanliness and good ventilation are the chief factors in the equation of successful surgery.

The success which has already attended some of our surgeons in the very worst cases of wounded intestine, should give us hope for better things to come. Dr. Bull, of New York, reports a case with seven perforations of the gut, and 1)r. J. 13. Hamilton another with eleven perforations, both treated by laparotomy, and both made complete recoveries.

The subject should surely enlist in its investigation the best thought and the best work of the profession.

\section{THE ETIOLOGY OF RACHITIS.'}

BY lI. C. HAVliN, M.I)., or Hoston.

Although we can hardly aceept Jenner's statement that rachitis is the most common, the most important, and in its effects the most fatal of the diseases affecting children, as holding true in this country, it is yet sufficiently common to make its prevention of great importance to the public health. It is, typically, a preventable disease - so far as serious results to the individual are concerned-if proper treatment is instituted early enough. It might, probably, be absolutely prevented, if we knew the ultimate causes. My purpose is to briefly present the statistics I have gathered as to the effect of the commonly accepted causes of rachitis on its production in this city.

During the past three years, at the West lind Dispensary for Children, there were in attendance-

Total number under 7 years............................ 2,516 .

Percentage of rachlics................................. 75.

Total ntage of rachitics.....................................

"otal number of colored under 7 years..............................

Percentage of colored rachitics......

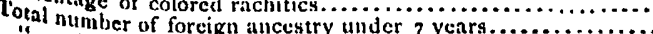

Percenta " " "

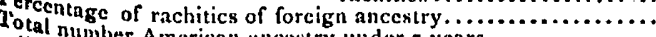

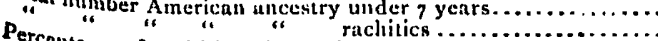

Percentage of rachitics of American ancestry.....................

" "mber of ancestry unk "

RACE.

Classifying the rachitics as to race, we find, of the number where it is known: Colored, thirty-eight; foreign, twenty; American, four. Of the twenty rachitics of foreign ancestry (Provinces included), there were: Portuguese, three; Italian, two; Irish, two; English, two; French, one; Nova Scotian, two; Rus. foren, one; German, one; of mixed parentage, both two orefour; of mixed parentage, father American, two; of mixed parentage, mother American, one.

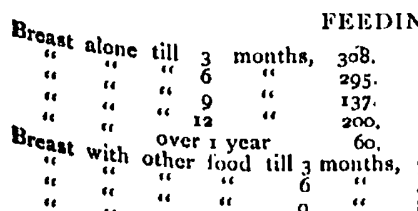
FEIEDING.

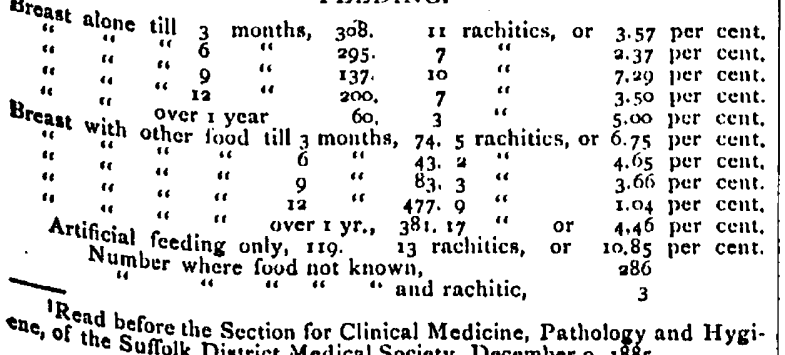
. 50 . 3.50 . 38. 42.79. 20. (1) there is no evichent fallare of nitrition on the part of the child. I hope later to present some analysis of the milk of women nursing rachitic children.

Assuming, then, the preponderance of rachitis among the colored race in Boston, and granting the effect of the diet they receive not to be a marked one, at least, as I think we are justified in doing, the question arises as to what other cause may be acting, peculiar not to any racial dyscrasia, but resulting from racial or acquired character and habits; that is, are the quarters of the city in which they live more densely crowded, are the tenements they inhabit more damp and cold or having less sumlight; are their habits of caring for their children, especially as to taking them out of doors, different from those of the equally destitute of other nationalities? I can only give my opinion, that all these questions must be answered in the negative. I have no positive information, and hope I may obtain some from others to-night. My experience has been, that the colored are more lavish in expenditure for food and rent than other poor, taken as a class, that in equal ways their 